April 2015

\title{
Quality of life among women with symptoms of gynecological morbidities: results of a cross-sectional study in Karachi, Pakistan
}

\author{
Neelofar Sami \\ Willows Foundation, Karachi, Pakistan \\ Tazeen Saeed Ali \\ Aga Khan University, tazeen.ali@aku.edu \\ Muhammad Osama \\ Dow Medical College, Karachi, Pakistan
}

Follow this and additional works at: http://ecommons.aku.edu/pakistan_fhs_mc_chs_chs

Part of the Family Medicine Commons, and the Public Health Commons

\section{Recommended Citation}

Sami, N., Ali, T. S., Osama, M. (2015). Quality of life among women with symptoms of gynecological morbidities: results of a cross-sectional study in Karachi, Pakistan. Journal of Obstetrics and Gynaecology Research, 41(4), 608-614.

Available at: http://ecommons.aku.edu/pakistan_fhs_mc_chs_chs/273 


\title{
Quality of life among women with symptoms of gynecological morbidities: Results of a cross-sectional study in Karachi, Pakistan
}

\author{
Neelofar Sami ${ }^{1}$, Tazeen Saeed $\mathrm{Ali}^{2}$ and Muhammad Osama ${ }^{3}$ \\ ${ }^{1}$ Willows Foundation, ${ }^{2}$ School of Nursing and Department of Community Health Sciences, Aga Khan University, and ${ }^{3}$ Dow \\ Medical College, Dow University of Health Sciences, Karachi, Pakistan
}

\begin{abstract}
Aims: A population-based cross-sectional study design was used to study the effects of symptoms of various gynecological morbidities (GM) on health-related quality of life (HRQoL) of women, residents of squatter settlements of Karachi, Pakistan.

Material and Methods: This cross-sectional study was conducted in squatter settlements of Karachi from September 2012 to August 2013, with 1002 married, non-pregnant women. After obtaining written informed consent from every participant, a structured questionnaire was used to collect information about symptoms of GM and their effect on four domains of HRQoL (physical, social, functional and financial domains).

Results: Of 1002 women who participated in the study, 578 reported suffering from one or more symptoms of GM. The most commonly reported symptoms were foul-smelling vaginal discharge, dysmenorrhea and uterovaginal prolapse while the least reported symptom was post-coital bleeding. Symptoms of GM were found to have a negative impact on HRQoL. Approximately one-third of women with the symptoms of GM reported having negative influences on the physical, financial and functional domains of HRQoL with social domain being comparatively less affected. Compared to other symptoms, dysmenorrhea and uterovaginal prolapse were reported to be mostly associated with poor HRQoL of women.

Conclusion: The concept of HRQoL has been kept marginal and inconspicuous by clinicians. In order to achieve the psychosocial satisfaction of the patient, the focus needs to be diverted to all domains of HRQoL.

Key words: domains, dysmenorrhea, gynecological morbidity, health-related quality of life, uterovaginal prolapse.
\end{abstract}

\section{Introduction}

The World Health Organization has defined 'reproductive health' as a state of complete physical, mental and social well-being and not merely an absence of disease in all matters relating to the reproductive system and its functions and processes. ${ }^{1}$ Maternal mortality has long been considered as the main indicator of a woman's reproductive health with increasing interna- tional concern about provision of health care during pregnancy, child bearing and the postnatal period. ${ }^{2}$ In comparison, scant attention has been paid to the issues related to reproductive morbidity, which are much more common and gravely affect women's lives. ${ }^{3}$

Reproductive morbidity encompasses health problems related to reproductive organs and functions, including child bearing, and refers to the diseases that affect the reproductive system, not necessarily as a

Received: April 22014.

Accepted: September 12014.

Reprint request to: Mr Muhammad Osama, Dow Medical College, Dow University of Health Sciences, Baba-E-Urdu Road, Karachi 74200, Pakistan. Email: Osama_dmc17@yahoo.com 
consequence of reproduction. ${ }^{4}$ This could be broadly categorized into obstetric, contraceptive and gynecological morbidity (GM). GM is defined as 'structural and functional disorders of genital tract not related to pregnancy, delivery and the puerperium but may be related to sexual behavior'. ${ }^{4}$ Unlike obstetric and contraceptive morbidity, GM is not related to any event in a woman's life. These are more common, affect the daily routine life of a woman and could have serious consequences. Moreover, these morbidities might have a negative impact on her health-related quality of life (HRQoL), which is an individual's overall satisfaction with life and the general sense of well-being. ${ }^{5} \mathrm{HRQoL}$ of a person with any morbidity is multidimensional with four broad domains: physical, functional, social and psychological. Other important health-related factors, like vitality, pain, anxiety and depression, are often included within these four categories. ${ }^{5} \mathrm{GM}$ are notorious for negatively affecting the HRQoL of women are often ignored not only by women ${ }^{6}$ but by health providers, planners and researchers too. ${ }^{7}$

Poor HRQoL for women with GM could be due to infertility, menstrual and coital disorders, fistula, uterovaginal prolapse or sexually transmitted infections with consequences for all four domains. The situation becomes particularly gloomy for women from developing countries as the QoL is further exasperated by their poor socioeconomic conditions. Their illiteracy, hesitation in discussing the sensitive subject of the genital tract and its functions, ignorance, lack of empowerment, lack of awareness and inability to afford seeking health care result in delay in or failure for opting for scientific management ending up in various complications. ${ }^{8-10}$

Additionally, such morbidities have been reported to affect a woman's marital life and she may become a victim of verbal and physical abuse and abandonment or face the social consequences, such as threat of divorce by her husband. ${ }^{11}$ These problems could be attributed to multiple factors, including morbidity per $s e^{12}$ poor sexual relationships due to the symptoms of morbidities $^{13}$ or a woman's inability to fulfill her routine activities due to the symptoms/morbidities, a mandatory perceived role of a woman in developing countries. ${ }^{14}$

Though there is a dearth of data in Pakistan, GM are not uncommon. A few community and facility-based studies have revealed the prevalence of various morbidities as follows: uterovaginal prolapse (11-12\%), vaginal discharge $(77 \%)$, and menstrual problems $(82 \%))^{7,15,16}$ Some women report multiple morbidities and studies conducted in squatter settlements of Karachi reported that nearly half of the women (55\%) reported at least one type of morbidity while one-fifth of the women $(20 \%)$ reported two or more types. ${ }^{6,16}$ The aforementioned studies divulge the high burden of the problem. Interestingly, none of these studies have evaluated the affects of these morbidities on women's HRQoL. The present study describes the impact of symptoms of various types of GM on HRQoL. It was the part of the study conducted to assess the prevalence of various GM among women in squatter settlements of Karachi, Pakistan.

\section{Methods}

\section{Study site and population}

The study was conducted in squatter settlements of the metropolitan city of Karachi, Pakistan, which has a population of 23.5 million as of April 2013. ${ }^{17}$ For administrative purposes, the city has been divided into 18 towns which are sub-divided into 178 union councils (UC) with 6-15 UC in each town.

The study was conducted in collaboration with the National Program for Family Planning (FP) and Primary Health Care (PHC). The program serves the poor communities, residing in rural and peri-urban areas, and provides FP and PHC services at their doorsteps through Lady Health Workers (LHW). Each LHW is responsible for serving the residents of 150 households through monthly home visits and static health houses established within their residence.

\section{Sampling strategy and enrollment}

The study was conducted from September 2012 until August 2013. The multi-stage cluster sampling design identified the respondents. Out of the 18 towns, three towns and one UC from each town were randomly selected. The calculated sample size (1050) with 5\% bond on error and $95 \%$ confidence interval was divided equally into three segments so that a total of 350 respondents were selected from each UC. The household information was obtained from the National program for FP and PHC. A computerized list of all the households in three selected UC was generated. A random sample of households was drawn for enrolling married non-pregnant women aged 15-49 years. Only one woman from each household was enrolled. One woman was randomly selected from households with more than one eligible respondent. The study was approved by the ethical review committee in Aga Khan 
University. Written, informed consent was obtained from all participating women.

\section{Data collection}

Women who consented to participate in the study were administered a questionnaire by trained interviewers. Information was collected on the following aspects: menstrual, sexual and obstetric history, gynecologic symptoms (including vaginal discharge, itching, sores or ulcers in the genital area, backache, lower abdominal pain, prolapse, frequency of and burning/pain during micturition) and women's health-seeking behavior (treatment sought, health-care providers consulted, reasons for not seeking treatment). Women with a particular symptom of GM were questioned further about the four domains of QoL (physical, social, financial and functional).

\section{Operational definitions}

\section{Gynecological symptoms}

The following symptoms were considered assuming they indicate one or more types of GM: genital ulcers, genital vesicles, irritation on genital area, vaginal discharge, lower abdominal pain, backache, genital prolapse, difficulty in conceiving, menstrual irregularities, dysmenorrhea, post-coital bleeding, dyspareunia and symptoms related to micturition (burning, frequency, pain).

The following questions were asked for assessing four domains of HRQoL:

- Physical domain: Women were asked about the intensity of individual symptoms. Those who described their symptoms as 'moderate, severe or unbearable' were regarded as 'intensity of symptoms negatively affected the physical domain of HRQoL'. All others were declared 'physical domain of HRQoL not affected by the severity of the symptom'.

- Social domain: For this paper, the effect of any symptom and the related morbidity on marital relationship was considered under social domain. Women were asked if their marital life was affected due to the symptom. Those who responded 'Yes' were regarded as 'social domain of HRQoL was negatively affected by the symptoms'. All others were declared 'social domain of HRQoL was not affected by the symptoms'.

- Functional domain: For this paper, the effect of any symptom and the related morbidity on women's daily routine work was considered under functional domain. Women were asked if their daily routine work was affected due to the symptom. Those who responded 'Yes' were regarded as 'functional domain of HRQoL was negatively affected due to the symptoms'. All others were regarded as 'functional domain of HRQoL not affected by symptoms'.

- Financial domain: All women who did not seek treatment for the symptoms or did not complete the treatment advised due to financial reasons, that is, non-affordability, were regarded as 'financial domain of HRQoL was negatively affected by symptoms'. All others were regarded as 'financial domain of HRQoL not affected'.

\section{Statistical methods}

Data were double-entered using Epi-Info and error rate was less than $1 \%$. The statistical analyses were done using sPSs 17.0 for Windows.

\section{Results}

\section{Participation}

The calculated sample size was 1050 but a total of 1002 women were actually interviewed with a response rate of $95.4 \%$. The main reasons for declining to participate in the study included lack of permission from the family, fear of getting some disease diagnosed and nonavailability of husbands to grant permission for the women to participate in the study.

\section{Sociodemographic characteristics}

On average, women and their husbands were 31.0 and 33.2 years old, respectively (Table 1 ). Nearly one-third of the women were illiterate. The mean ages of the women at the time of marriage and menarche were $18.3 \pm 4.0$ and $13.2 \pm 1.1$ years, respectively. Of the 1002 women, 123 reported (12.2\%) being infertile and did not have any live children. The remaining 879 women reported a total of 3892 pregnancies. A little over $40 \%$ reported four or more pregnancies.

\section{Prevalence of symptoms of GM}

A total of $424(42.3 \%)$ women reported being asymptomatic for any GM. The prevalence of symptoms of GM was found to be $57.7 \%$ as 578 women reported suffering from symptoms of GM. The most commonly reported symptoms were foul-smelling vaginal discharge, backache, dysmenorrhea and uterovaginal prolapse while the least reported symptom was post-coital bleeding (Table 2). 
Table 1 Distribution of married women aged 15-49 years according to selected social, demographic and reproductive characteristics, Karachi, 2012-2013

\begin{tabular}{lc}
\hline Variables & $\begin{array}{c}\text { Women } \\
(n=1002)\end{array}$ \\
\hline Age in years & \\
Mean age $(31.0 \pm 6.8)$ & $6.1 \%$ \\
$<20$ & $47.2 \%$ \\
$21-30$ & $38.9 \%$ \\
$31-40$ & $7.8 \%$ \\
$41-46$ & \\
Literacy status & $36.9 \%$ \\
Illiterate & $14.2 \%$ \\
Madrasa/Religious education & $17.4 \%$ \\
Class 1-5 & $24.9 \%$ \\
Class 6-10 & $6.6 \%$ \\
Class 11 \& above & \\
Number of pregnancies (mean number of pregnancies \\
$3.5 \pm 2.2)$ & \\
0 & $3.0 \%$ \\
$1-3$ & $55.5 \%$ \\
$4-6$ & $30.2 \%$ \\
$\geq 7$ & $11.3 \%$ \\
\hline
\end{tabular}

Table 2 Prevalence of symptoms of gynecological morbidities among women from Karachi, Pakistan $(n=1002)$

\begin{tabular}{lcc}
\hline Symptoms & $n$ & $\% \dagger$ \\
\hline Backache & 212 & 21.5 \\
Lower abdominal pain & 185 & 18.4 \\
Irritation on genital area & 109 & 10.8 \\
Abnormal vaginal discharge & 298 & 29.7 \\
Uterovaginal prolapse & 174 & 17.5 \\
Dysmenorrhea & 178 & 17.6 \\
Irregular menstrual cycle & 117 & 11.7 \\
Abnormal menstrual bleeding & 76 & 7.5 \\
Painful micturition & 148 & 14.6 \\
Dyspareunia & 98 & 9.7 \\
Post-coital bleeding & 12 & 1.2 \\
\hline
\end{tabular}

tMultiple responses, do not add up to $100 \%$.

Of the symptomatic women, one-third (33.6\%) reported suffering from at least one symptom of GM. The remaining had two or more symptoms. Certain combinations of symptoms were found to be common for specific morbidity: women with uterovaginal prolapsed frequently reported vaginal discharge, backache and/or dysuria; women with dysmenorrhea commonly reported backache. Similarly, vulvar itching was common among women who reported to have vaginal discharge.

\section{Symptoms of GM and their relation with HRQoL}

For each symptom reported, women were questioned about their HRQoL and questions were asked under four domains: physical, functional, social and financial.

For the physical domain, almost one-third of women with complaints of dysmenorrhea, vaginal discharge, uterovaginal prolapse, lower abdominal pain and backache reported their symptoms to be markedly moderate to severe/unbearable.

For the functional domain, the most commonly reported symptom that affected a woman's daily routine life was uterovaginal prolapse. Almost $90 \%$ of women with uterovaginal prolapse reported an inability to complete their daily routine work. The other symptoms that affected the daily routine life of women were related to menstruation, with $42 \%$ and $52 \%$ of women suffering from dysmenorrhea and abnormal bleeding pattern, respectively, reported as a negative influence on functional domain. Post-coital bleeding affected the daily routine life of only $8 \%$ of the women.

For social domain, the most commonly reported symptoms were abnormal menstrual bleeding and dyspareunia, as mentioned by $62 \%$ and $55 \%$ of women, respectively. Only $5 \%$ of the women with dysmenorrhea reported their marital relationships to be negatively affected by the symptom.

For the financial domain, for every symptom except uterovaginal prolapse and dysuria, almost one-third of the women reported facing a financial dilemma that affected their health-seeking behavior. For uterovaginal prolapse, $42 \%$ of women reported facing financial problems. Only a small proportion of women with dysuria reported facing monetary issues (Table 3).

\section{Discussion}

This study indicates a high prevalence of symptoms of GM among married women aged 15-49 years residing in squatter settlements of Karachi. Vaginal discharge and dysmenorrhea were found to be the most commonly reported symptoms, and post-coital bleeding was the least commonly reported. The prevalence of symptoms of GM in our study shows similar findings reported by other community-based studies conducted in Pakistan, ${ }^{7,16}$ in rural areas of Karnataka and Gujarat ${ }^{18}$ and in Indian urban slums. ${ }^{19}$ Nearly one-third (33.6\%) of our study population reported having at least one symptom related to any GM. The studies conducted in India showed the prevalence of at least one symptom 
Table 3 Women with symptoms of gynecological morbidity and their reported health-related quality of life

\begin{tabular}{lcccc}
\hline Symptoms & $\begin{array}{l}\text { Physical } \\
n(\%)\end{array}$ & $\begin{array}{l}\text { Financial } \\
n(\%)\end{array}$ & $\begin{array}{l}\text { Functional } \\
n(\%)\end{array}$ & $\begin{array}{l}\text { Social } \\
n(\%)\end{array}$ \\
\hline Backache $(n=212)$ & $69(32.5)$ & $72(33.9)$ & $59(27.8)$ & $28(13.2)$ \\
Lower abdominal pain $(n=185)$ & $61(32.9)$ & $54(29.1)$ & $66(35.6)$ & $16(8.6)$ \\
Irritation on genital area $(n=109)$ & $26(23.8)$ & $33(30.3)$ & $31(28.4)$ & $21(19.2)$ \\
Abnormal vaginal discharge $(n=298)$ & $102(34.2)$ & $78(26.1)$ & $67(22.4)$ & $52(17.4)$ \\
Uterovaginal prolapse $(n=174)$ & $53(30.4)$ & $75(43.1)$ & $156(89.6)$ & $29(16.6)$ \\
Dysmenorrhea $(n=178)$ & $58(32.5)$ & $55(30.8)$ & $75(42.1)$ & $10(5.6)$ \\
Irregular menstrual cycle $(n=117)$ & $24(20.5)$ & $35(30.0)$ & $32(27.3)$ & $57(48.7)$ \\
Abnormal bleeding $(n=76)$ & $17(22.3)$ & $24(31.5)$ & $40(52.6)$ & $47(61.8)$ \\
Painful micturition $(n=148)$ & $35(23.6)$ & $11(7.4)$ & $45(30.4)$ & $18(12.1)$ \\
Dyspareunia $(n=98)$ & $26(26.5)$ & $30(30.6)$ & $12(12.2)$ & $54(55.1)$ \\
Post-coital bleeding $(n=12)$ & $2(16.6)$ & $4(33.3)$ & $1(8.3)$ & $4(33.3)$ \\
\hline
\end{tabular}

of GM from $33 \%{ }^{18}$ to $55 \% .^{20,21}$ Multiple morbidities faced by a woman are also prevalent. Our study has revealed 1.6 symptoms per woman and a similar trend has been shown by a study conducted in Karnataka, India where the prevalence of gynecological problems per woman was $1.51 .{ }^{22}$

Symptoms of GM impose severe negative impact on the HRQoL of the women. However, the matter of HRQoL has always been viewed as 'soft' or subjective by clinicians and regarded as less meaningful than pathological aspects as revealed by Van der Vaart for women with pelvic floor dysfunction. ${ }^{23}$

Our study reports a significant negative impact of these symptoms on the physical, financial and functional domains of HRQoL. In this regard, the social domain was least affected compared to the other three domains.

Physical domain was mostly reported to be affected by dysmenorrhea, vaginal discharge, uterovaginal prolapse, lower abdominal pain and backache. Our study reported a high prevalence of these symptoms among the women investigated (Table 2). Therefore, a higher proportion of women in our study were likely to have a negative impact upon physical domain of HRQoL. Parallel trends have been found in a study conducted in the Netherlands that showed the correlation of symptoms of urogenital dysfunction and their negative impact upon the physical domain of HRQoL. ${ }^{24}$

For the financial domain, all of the symptoms of GM, except dysuria, were found to negatively affect the HRQoL for almost one-third of the women. The possible explanation could be the poor socioeconomic status of the women as the study was conducted in squatter settlements of Karachi where the majority of women belong to a low socioeconomic class.
Concerning functional domain, uterovaginal prolapse, abnormal menstrual bleeding and dysmenorrhea were the main symptoms leading to a negative influence on the daily routine life for $90 \%, 52 \%$ and $42 \%$ of the women, respectively. These symptoms were most prevalent too and their negative impact on functional domain is quite alarming as these symptoms can lead to massive hindrances in the normal daily routine work by the women with its consequences. ${ }^{12,25}$ A study on a Dutch population showed negative influence of symptoms of urogenital dysfunctions on the functional aspect of HRQoL. ${ }^{24}$ Another cross-sectional study conducted in Turkey identified that dysmenorrhea is a common symptom among high school girls and negatively affects the functional domain of HRQoL. ${ }^{26}$ An important finding of our study is that almost $90 \%$ of the women with uterovaginal prolapse reported disturbances in the functional domain. This could be due to the types of prolapse as second- and third-degree prolapse hinder the performance of daily activities.

The social domain was reported to be least affected by most of the symptoms of GM. However, women with abnormal menstrual bleeding, dyspareunia and post-coital bleeding reported their social domain as being negatively affected. We cannot generalize this statement as the limitation of the study is that for social domain, we only considered marital relationships and other social factors were not explored.

The study shows that two important symptoms negatively affecting the HRQoL of the women are menstrual symptoms and genital prolapse.

Women are particularly affected by menstrual symptoms as they have to face these each month with all domains of QoL compromised. Of the menstrual symptoms, irregular cycles and abnormal bleeding 
negatively affect the social domain too, resulting in poor marital relationships with its consequences. Similar findings were reported in a dissertation that focused on a study with girls in Taiwan. The results revealed that dysmenorrhea has a negative impact on an individual's ability to perform daily activities, upsetting productivity and performance and is associated with stress, so their daily life, including physical and social life, is disturbed. ${ }^{27}$ Our study has additionally identified that women's functional life could also be affected by dysmenorrhea. Another study conducted in urban Karachi, Pakistan showed that girls with dysmenorrhea face social and physical immobility. ${ }^{28}$ A study conducted by Onur et al. seconds the findings of our study. ${ }^{29}$

The other symptom affecting the overall quality of life significantly is genital prolapse, which leads to a notable influence upon all domains of HRQoL. Parallel trends were found in a study from Karachi, Pakistan reporting that vaginal prolapse can hinder a woman's daily activities of life and can further lead to painful coitus, which further demeans her in the eyes of her husband. Thus, the woman is unable to sexually satisfy her husband and this puts an additional stress on their relationship. ${ }^{30}$ Digesu et al. used a validated tool and identified that if a woman has asymptomatic vaginal prolapse, she often does not report any effect on QoL. However, women with symptomatic prolapse reported a negative effect on QoL. ${ }^{31}$ On this basis, one can infer that our study participants, who reported to have a negative impact upon HRQoL, could be the patients of second- or third-degree prolapse. Higher degrees badly affect the daily routine of women, such as walking, sitting, standing, urination, and defecation, with dominant impact on physical and functional domains of HRQoL.

There are certain limitations of the study. For all reported symptoms, we relied on information provided by the women. Most of the women in our samples were illiterate with the possibility of information biases. An important limitation of our study was that we were not able to assess the impact of symptoms of GM on psychological domain of HRQoL. Studies have revealed the association of gynecological symptoms and psychological health. ${ }^{32}$ However, the project team needed special training for that, which was beyond the scope of our project. We strongly recommend that future studies need to asses this domain efficiently, especially for evaluating the HRQoL.

The concept of HRQoL has been kept marginal and inconspicuous. The health-care providers usually follow the traditional end-points, which are mainly focused on the biological and physiological outcomes, inadvertently ignoring the issue of HRQoL of a patient. HRQoL measures represent a patient's perception of outcome of treatment. Physiologic measures provide information to the clinician but are of limited interest to the patient. Thus the subject of HRQoL should not be ignored and focus needs to be distributed equally to both physiological outcomes as well as to all aspects of HRQoL in order to meet the psychosocial satisfaction of women suffering from GM.

\section{Acknowledgments}

The authors acknowledge the contribution made by the community women without which the study could not be completed. The support provided by all Town Health Officers and Lady Health Workers from the catchment areas is much appreciated. The study was funded by The University Research Council grant of Aga Khan University, Karachi, Pakistan.

\section{Disclosure}

The authors declare that there is no conflict of interests as defined by the guidelines of the International Committee of Medical Journal Editors (ICMJE; http://www.icmje.org/).

\section{References}

1. United Nations. Program of Action Adopted at the International Conference on Population and Development, Cairo, 5-13th September 1994. New York: UN, 1994.

2. World Health Organization. Reproductive Health Indicators Guidelines for their Generation, Interpretation and Analysis for Global Monitoring. Geneva: Department of Reproductive Health and Research, WHO, 2006; 63. Report No.: ISBN 924 156315 X.

3. Bonetti TR, Erpelding A, Pathak LR. Reproductive Morbidity, A Neglected Issue? Report of a Clinic Based Study in Farwestern Nepal, Kathmandu, Nepal, 2002.

4. World Health Organization. Measuring Reproductive Morbidity. Report of a technical working group, Geneva: WHO, 1990.

5. Ware JE. The status of health assessment 1994. Annu Rev Public Health 1995; 16: 327-354.

6. World Health Organization. DALYs and Reproductive Health. Report of an informal consultation. Geneva: WHO/ Division of RH, April 1998, pp. 27-28.

7. Zafar S, Mehmood G, Haq AN. Burden of gynecological disease in a tertiary hospital: Two years audit of Outpatient Department at PIMS. J Pak Med Assoc 2004; 54: 513-515. 
8. Basu P, Sarkar S, Mukherjee S et al. Women's perceptions and social barriers determine compliance to cervical screening: Results from a population based study in India. Cancer Detect Prev 2006; 30: 369-374.

9. Jejeebhoy S, Koeing M. Social context of gynecological morbidity: correlates, consequences and health seeking behavior. In: Jejeebhoy S, Koeing M, Elias C (eds). Investigating Reproductive Tract Infections and Other Gynecological Disorders. London: Cambridge University Press, 2003; 30-81.

10. Gaash B, Kausar R, Bhan R, Bashir S. Reproductive Tract Infections in Kargil: A Community-based Study. Health and Population-Perspectives and Issues 2005; 28: 1-8.

11. Stephenson R, Koenig M, Ahmed S. Domestic violence and symptoms of gynecologic morbidity among women in North India. Int Fam Plan Perspect 2006; 32: 201-208.

12. Handa VL, Harvey L, Cundiff GW, Siddique SA, Kjerulff KH. Sexual function among women with urinary incontinence and pelvic organ prolapse. Am J Obstet Gynecol 2004; 191: 751-756.

13. Ali TS, Krantz G, Gul R, Asad N, Johansson E, Mogren I. Gender roles and their influence on life prospects for women in urban Karachi, Pakistan: A qualitative study. Glob Health Action 2011 doi 10.3402/gha.v4i0.7448.

14. Shah M, Khan R, Naushad K, Jadoon MA, Alam I. Women being the most neglected agent in the South Asian societies. Pak J Life Soc Sci 2006; 4: 81-85.

15. Maternity and Child Welfare Association of Pakistan. Reproductive morbidity in an urban community of Lahore. Zafar Sons Printers, Lahore, Report. 1992-1993; pp. 29, 40.

16. Sajan F, Fikree FF. Perceived gynecological morbidity among young ever-married women living in squatter settlements of Karachi, Pakistan. J Pak Med Assoc 1999; 49: 9297.

17. Karachi Metropolitan Corporation (KMC). (2013). Karachi the gateway to Pakistan. [Cited 19 Aug 2013.] Available from URL: http://www.kmc.gos.pk.

18. Patel P. Illness beliefs and health-seeking behaviour of the Bhil women of Panchamahal District, Gujarat State. In: Gittlesohn J, Bentley ME, Pelto PJ (eds). Listening to Women Talk about Their Health: Issues and Evidence from India. New Delhi: Har Anand Publications, 1994; 55-56.

19. Garg S, Sharma N, Bhalla P. Reproductive morbidity in an Indian urban slum: Need for health action. Sex Transm Infect 2002; 78: 68-69.
20. Bhatia JC, Cleland J. Self reported symptoms of gynecological morbidity and their treatment in south India. Stud Fam Plann 1995; 26: 203-216.

21. Bang RA, Baitule M, Sarmukaddam S, Bang AT, Choudhary $\mathrm{Y}$, Tale O. High prevalence of gynecological diseases in rural Indian women. Lancet 1989; 333: 85-88.

22. Poornima S, Katti SM, Mallapur MD, Vinay M. Gynecological problems of married women in the reproductive age group of urban Belgaum, Karnataka. Al Ameen J Med Sci 2013; 6: 226230.

23. van der Vaart $\mathrm{CH}$. Pelvic Floor Dysfunction and Quality of Life in Women (Dissertation). Zeist: University of Utrecht, 2001.

24. van der Vaart $\mathrm{CH}$, de Leeuw JR, Roovers JP, Heintz AP. Measuring health-related quality of life in women with urogenital dysfunction: The urogenital distress inventory and incontinence impact questionnaire revisited. Neurourol Urodyn 2003; 22: 97-104.

25. Ross JL, Laston SL, Nahar K, Muna L, Nahar P, Pelto PJ. Women's health priorities: Cultural perspectives on illness in rural Bangladesh. Health 1998; 2: 91-110.

26. Unsal A, Ayranci U, Tozun M, Arslan G, Calik E. Prevalence of dysmenorrhea and its effect on quality of life among a group of female university students. Ups J Med Sci 2010; 115: 138-145.

27. Lu I-C. Dysmenorrhea and Related Factors in Taiwanese Adolescent Girls (Dissertation). Austin: University of Texas at Austin, 2010.

28. Ali TS, Rizvi SN. Menstrual knowledge and practices of female adolescents in urban Karachi, Pakistan. J Adolesc 2010; 33: 531-541.

29. Onur O, Gumus I, Derbent A. Impact of home-based exercise on quality of life of women with primary dysmenorrhea. $S$ Afr J Obstet Gynecol 2012; 18: 15-18.

30. Rabbani F, Qureshi F, Rizvi N. Perspectives on domestic violence: Case study from Karachi, Pakistan. East Mediterr Health J 2008; 14: 415-426.

31. Digesu GA, Khullar V, Cardozo K, Robinson D, Salvatore S. P-QOL: a validated questionnaire to assess the symptoms and quality of life of women with urogenital prolapse. Int Urogynecol J Pelvic Floor Dysfunct 2005; 16: 176-181.

32. Patel V, Oomman N. Mental health matters, too: Gynecological symptoms and depression in South Asia. Reprod Health Matters 1999; 7: 30-38. 